\title{
Cardiovascular calcification in chronic hemodialysis patients: Contributors interplay
}

\author{
Ashraf Abd El-Khalik Barakat ${ }^{1}$, Manar Abd El-Rouf Raafat Ameen ${ }^{2}$, Amna Ahmed Metwaly ${ }^{1}$, \\ Fatma Mohammed Nasr ${ }^{1}$, Nevine Sherif Ali Khalil ${ }^{2}$, Iris Nessim ${ }^{3}$ \\ ${ }^{1}$ Intensive Care Department, Theodor Bilharz Research Institute, Cairo, Egypt \\ ${ }^{2}$ Nephrology Department, Theodor Bilharz Research Institute, Cairo, Egypt \\ ${ }^{3}$ Clinical Chemistry Department, Theodor Bilharz Research Institute, Cairo, Egypt
}

\section{Email address:}

dr.ashraf.a@hotmail.com (A. A. El-Khalik B.),manar_raafat@hotmail.com (M. A. El-Rouf R. A.), amnametwaly@ hotmail.com (A. A. Metwaly), fatma_elwakeel@live.com (F. M. Nasr), nevinesherif@yahoo.com (N. S. A. Khalil), iris_nessim@yohoo.com (I. Nessim)

\section{To cite this article:}

Ashraf Abd El-Khalik Barakat, Manar Abd El-Rouf Raafat Ameen, Amna Ahmed Metwaly, Fatma Mohammed Nasr, Nevine Sherif Ali Khalil, Iris Nessim. Cardiovascular Calcification in Chronic Hemodialysis Patients: Contributors Interplay. American Journal of Life Sciences. Vol. 2, No. 5, 2014, pp. 251-259. doi: 10.11648/j.ajls.20140205.11

\begin{abstract}
Traditional cardiovascular risk factors are common among chronic kidney disease (CKD) patients. However the high prevalence of atherosclerosis and arterial calcification in CKD is far beyond the explanation by common cardiovascular risk factors. The aim of this study is to determine the incidence of cardiovascular calcification and its relation to demographic data, hemodialysis data and laboratory biomarkers and to evaluate the cardiovascular risk of atherosclerosis in hemodialysis patients. Fourty CKD patients on regular hemodialysis and twenty healthy volunteers were subjected to echocardiography, carotid ultrasound and laboratory studies including serum parathrmone $(\mathrm{PTH}), 25(\mathrm{OH})$ vitamin $\mathrm{D}$, feutin and osteoprotegerin levels (OPG). The echocardiographic data showed a statistically significant increase in interventricular septum thickness (IVST), posterior wall thickness (PWT) and left ventricular mass index (LVMI) in patients group compared to the controls. Thirty patients (75\%) had valvular calcification. There was significant increase in carotid intima-media thickness (CIMT) in patients group. Serum levels of Ph, PTH and Osteoprotegerin were significantly increased, however, serum levels of Ca, Vitamin D and Feutin were significantly decreased in patients group. Serum level of $\mathrm{Ph}$, and Osteoprotogerin were significantly increased while Vitamin D and feutin were significantly decreased in patients with valvular calcification compared to patients without valvular calcifications. The level of Vitamin D and Fetuin were negatively correlated with creatinine, PTH and osteoprotogerin. While, the level of osteoprotogerin and PTH were positively correlated with creatinine and with each other, they were negatively correlated with HDL-c and eGFR. CIMT was positively correlated with LVMI, PWT, urea, creatinine, CRP, Ca and was negatively correlated with EF\%, eGFR, HDL-c, vitamin D and Feutin. We concluded that hemodialysis patients with valvular calcifications were older in age, with a longer hemodialysis duration and showed higher Ph level, Ca x P product and OPG level and lower 25(OH)-vitamin D and fetuin A level. Also, they showed lower EF \% and were on lower doses of alphacalcidol and higher doses of calcium compared to patients without valvular calcifications. So, our study points to the importance of administration of active vitamin D derivatives to decrease the risk of valvular calcification and atherosclerosis. Serum fetuin A and osteoprotegerin can be used as a simple, easily performed biomarkers mirroring valvular calcification in hemodialysis patients. Further studies should be done to assess trials for the addition of fetuin A in the treatment of CKD patients to prevent the occurrence of calcification.
\end{abstract}

Keywords: Chronic Kidney Disease, 25(OH)-Vitamin D, Parathormone, Fetuin A, Osteoprotegerin, Vascular and Valvular Calcification, Carotid Intima-Media Thickness

\section{Introduction}

Chronic kidney disease (CKD) is an international public health epidemic that increases risk of premature death due to cardiovascular disease [1]. Traditional cardiovascular risk factors including aging, diabetes, hypertension and 
dyslipidemia are common among CKD patients. However the high prevalence of atherosclerosis and arterial calcification in CKD is far beyond the explanation by common cardiovascular risk factors [2]. Previous studies have demonstrated increasing prevalence of vascular calcification starting from early stages of CKD toward the end-stage renal disease. In a large cohort of CKD patients, the magnitude of coronary artery calcification (CAC) was independently and inversely associated with the estimated glomerular filtration rate (eGFR) [3]. In addition to common cardiovascular risk factors, other CKD-related factors such as phosphate retention, excess of calcium and prolonged dialysis vintage also contribute to the development of vascular calcification [4\&5].

Cardiovascular calcification is divided into three types, depending on the locations involved: arterial intimal calcification (AIC) [6], arterial medial calcification (AMC) [7] and valvular calcification (VC) [8].

The prevalence of cardiovascular calcification varies greatly. Previous studies have revealed a high prevalence of calcification, ranging from $28 \%$ to $77 \%$, of the aortic or the mitral valve in dialysis patients [9]. Abnormalities also include valvular and annular thickening thereby leading to regurgitation and/or stenosis [10]. London and his colleagues reported that $63.8 \%$ of their hemodialysis patients had arterial calcification [4]. Coronary artery calcification has also been shown to be more prevalent after the onset of dialysis, being present in $65 \%$ of those patients [11].

Carotid intima-media thickness (CIMT) is a surrogate marker for atherosclerosis and can be used to detect an accelerated disease process and subclinical disease [12]. Carotid intima-media thickness is greater in hemodialysis patients compared to the control group [13]. CIMT remained a consistent predictor of fatal cardiovascular events indicates that this measurement bears a prognostic value on the dialysis population. A $0.1-\mathrm{mm}$ increase in CIMT predicts a $24 \%$ higher risk for cardiovascular death [14 \& 15].

There is a strong association between chronic inflammation and disturbance of bone mineral metabolism in chronic hemodialysis patients [16]. The link between dysregulation of calcium, phosphate, and the parathyroid hormone, and cardiovascular calcification is controversial [17]. Hyperphosphatemia and secondary hyperparathyroidism, often goes along with an excess calcium load and is found to be associated with the progression of vascular calcification, particularly when calcium is used in combination with vitamin D [18 \& 19].

Vascular calcification in dialysis patients may be associated with increased calcium intake, increased serum calcium-phosphorus product, abnormal bone metabolism, and decreased vitamin D levels [20]. A study by Davies and his colleagues showed that vascular calcification was inversely correlated to serum level of vitamin D [21] and other retrospective studies by Mizobuchi and his colleagues showed similar findings [22].

Fetuin-A is a liver-derived potent systemic inhibitor of calcification and a negative acute phase reactant [23]. In addition to prevention of calcium and phosphate precipitation in the serum, fetuin-A protects from arterial media calcification by inhibiting vascular smooth musce cell (VSMC) apoptosis and preventing basic calcium particle nucleation in the extracellular matrix [24]. In hemodialysis (HD) patients, low fetuin-A levels have been associated with severe and extensive vascular calcification, as well as with increased all-cause and cardiovascular mortality [25 \&26].

Osteoprotegerin (OPG) is a soluble member of the tumor necrosis factor (TNF) receptor superfamily, produced by osteoblasts and vascular endothelial and smooth muscle cells [27]. It has an anti-osteoclastic effect being a soluble decoy receptor for the osteoclast activator RANKL (receptor activator of nuclear factor- $\kappa \mathrm{B}$ ligand). Moreover, it appears to be an important regulator of vascular calcification [28] and in HD patients, high OPG levels have been associated with vascular calcification and mortality [29\&26].

\section{Aim of the Work}

To determine the incidence of cardiovascular calcification using echocardiography and its relation to demographic data, hemodialysis data and laboratory biomarkers and to evaluate cardiovascular risk of atherosclerosis using high resolution $\mathrm{B}$ mode ultrasonography of the both common carotid arteries in regular haemodialysis patients in dialysis unit of Theodor Bilharz Research Institute.

\section{Subjects and Methods}

\subsection{Subjects}

The present study was conducted in Hemodialysis Unit, Theodor Bilharz Research Institute. Forty CKD patients on regular hemodialysis for more than 6 months, dialysed 3 times a week four-hourly sessions through arteriovenous fistula with standard acetate dialysate were included in the study fistula. In addition, 20 (age and sex-matched) healthy volunteers were chosen as a control group.

None of the patients had history of rheumatic or congenital heart disease.

All patients were provided by informed consent, and the ethical committee of hospital approved this study.

\subsection{Methods}

Patients and control were subjected to history taking and thorough clinical examination.

The following investigations were performed:

Electrocardiography: Twelve lead surface resting ECG was done

Echocardiography: Transthoracic echocardiographic measurements were performed according to the recommendations of the American Society of Echocardiography (30). M-mode, Two dimensional echocardiography and Doppler ultrasound studies (pulsed, continuous wave and color flow imaging) were made using a high resolution (ALT 5000 HDI) Toshiba Nemo 30 scanner equipped with a $2.5 \mathrm{mHz}$ transducer. 
B-mode Carotid ultrasonography: High resolution B mode ultrasonography of both the common carotid arteries were performed using an ultrasound machine (Toshiba Nemo 30 scanner) equipped with a $7.5 \mathrm{mHz}$ high resolution transducer.

Laboratory Investigations: Blood Samples: Ten ml fasting venous sample was taken before dialysis from antecubital vein divided into: $2 \mathrm{ml}$ on EDTA tubes for complete blood picture using $-1.6 \mathrm{ml}$ on sodium citrate for ESR and the rest on plain tubes (without anticoagulant). Blood was allowed to clot, centrifuged and serum was divided into 5 aliquots: the first for immediate performance of routine laboratory tests: liver functions (AST, ALT, ALP, total protein and albumin), renal functions (urea and creatinine), serum total calcium, serum phosphorus, cholesterol, triglyceride, HDL, LDL. serum electrolytes (sodium and potassium). The other four aliquots were stored at $-70{ }^{\circ} \mathrm{C}$ for remote estimation of serum parathormone, $25(\mathrm{OH})$ vitamin $\mathrm{D}$, serum fetuin and osteoprotegerin levels by ELISA technique (respectively). Repeated freezing and thawing was avoided.

Analytical methods:

Complete blood picture was performed using the automatic Hematology Analyzer Celtac-MEK 8118 (Nihon Kohden).

Routine liver, renal function tests and lipid profile were assessed using using automated analyzer Beckman coulter Synchron CX9 Pro. Serum electrolytes were measured using were assessed using fully automated instrument (AVL-9130) USA.

Specific estimation of: Parathormone level : Parathormone level was measured by enzyme linked immunosorbent assay (ELISA) using kit manufactured by BioSource, Neville, Belgium with minimal detectable concentration of $2 \mathrm{pg} / \mathrm{ml}$ (Intra-assay coefficient of variations (CVs) 1.1-2 \% and Inter-assay CVs $2.9-7.1 \%$ ).

\section{Statistical Analysis}

Statistical analysis was performed using SPSS version 17. Data were expressed as the mean \pm standard deviation (SD) for numerical variables. $\mathrm{P} \leq 0.05$ was considered to be statistically significant and $\mathrm{P}<0.01$ was considered to be highly statistically significant. A multiple stepwise linear regression analysis was performed to determine the independent factors of valvular calcification in hemodialysis patients.

\section{Results}

The demographic data of the patients group and the control group revealed mean ages $55.9 \pm 11.1$ years and $56.3 \pm 12.3$ years, respectively. In group 1 (patients group) 25 were males $(62.5 \%)$ and 15 were females $(37.5 \%)$, in group 2 (control group) 12 were males $(60 \%)$ and 8 were females $(40 \%)$. There were no significant differences between HD patients and controls regarding age \& gender. Nine patients had DM and 31 patients had hypertension. 12 patients were smokers. Eight patients had lower limb edema. Fifteen patients were complaining of chest pain, 12 patients from dyspnea, one patient had IHD by ECG, 6 patients had LVH by ECG and 19 patients had normal ECG. The duration of dialysis of the patients group was $5.9 \pm 3.6$ years. The SBP was significantly higher in patients compared to the controls $(\mathrm{P}<0.05)$ (table 1).

Table (1). Demographic data of the patients and the controls

\begin{tabular}{llll}
\hline & Patients $(\mathbf{n o}=\mathbf{4 0})$ & Control $(\mathbf{n o}=\mathbf{2 0})$ & P value \\
\hline Age (years) & $55.9 \pm 11.1$ & $56.3 \pm 12.3$ & $\mathrm{NS}$ \\
Gender Male & $25(62.5 \%)$ & $12(60 \%)$ & $\mathrm{NS}$ \\
$\begin{array}{l}\text { Female } \\
\text { Duration of dialysis } \\
\text { (years) }\end{array}$ & $15(37.5 \%)$ & $8(40 \%)$ & $\mathrm{NS}$ \\
BMI $(\mathrm{Kg} / \mathrm{m} 2)$ & $27.0 \pm 4.6$ & & $\mathrm{NS}$ \\
SBP $(\mathrm{mmHg})$ & $137 \pm 18.8$ & $26.8 \pm 5.9$ & .01 \\
DBP $(\mathrm{mmHg})$ & $83.6 \pm 9.8$ & $126 \pm 9.4$ & $\mathrm{NS}$ \\
Pulse $(\mathrm{beat} / \mathrm{min})$ & $83.1 \pm 17.3$ & $79.2 \pm 7.1$ & $\mathrm{NS}$ \\
\hline
\end{tabular}

$\mathrm{P}<0.05=$ significant

BMI, body mass index; SBP, systolic blood pressure; DBP, diastolic blood pressure.

The echocardiographic data showed a statistically significant increase in interventricular septum thickness (IVST), posterior wall thickness (PWT) and left ventricular mass index (LVMI) in patients group compared to the controls $(\mathrm{P}<0.01)$. Also, there was significant increase in CIMT in patients group compared to the controls $(\mathrm{P}<0.01)$. Twenty sex patients $(65 \%)$ had diastolic dysfunction while 20 patients $(50 \%)$ had wall motion abnormalities (table 2$)$. Also, thirty patients $(75 \%)$ had valvular calcification, $12(30 \%)$ had isolated aortic calcification, $8(20 \%)$ had isolated mitral calcification and $10(25 \%)$ had both mitral and aortic calcification, none had pulmonary or tricuspid valve calcification. $15(37.5 \%)$ patients had aortic regurge and 3 ( $10 \%$ ) patients had aortic stenosis while $10(25 \%)$ patients had mitral regurge.

Table (2). Comparison between Echocardiographic data and CIMT of the patients and controls

\begin{tabular}{lccc}
\hline & Patients (no=40) & Control $(\mathbf{n o}=\mathbf{2 0})$ & P value \\
\hline EDD $(\mathrm{mm})$ & $49.8 \pm 7.7$ & $51.5 \pm 7.2$ & $\mathrm{NS}$ \\
ESD(mm) & $33.0 \pm 5.5$ & $31.2 \pm 5.3$ & $\mathrm{NS}$ \\
FS\% & $37.3 \pm 9.1$ & $39.4 \pm 5.8$ & $\mathrm{NS}$ \\
EF\% & $63.4 \pm 10.0$ & $69.1 \pm 7.4$ & $\mathrm{NS}$ \\
IVST(mm) & $11.6 \pm 2.2$ & $8.8 \pm 1.2$ & $<0.01$ \\
PWT(mm) & $11.5 \pm 1.9$ & $8.8 \pm 1.3$ & $<0.01$ \\
LVMI(g/m2) & $57.9 \pm 13$ & $40.0 \pm 10.0$ & $<0.01$ \\
Wall motion & $20(50 \%)$ & 0 & $<0.01$ \\
abnormalities & $26(65 \%)$ & $2(10 \%)$ & $<0.01$ \\
Diastolic & & & \\
dysfunction & $30(75 \%)$ & $3(15 \%)$ & $<0.01$ \\
Valvular & $11 \pm .1 .8$ & $6 \pm 1.3$ & $<0.01$ \\
calcification & & & \\
CIMT(mm) & & & \\
\hline
\end{tabular}

$\mathrm{P}<0.05=$ significant, $\mathrm{P}<0.01=$ highly significant

EDD: end diastolic dimension, ESD: end systolic dimension, FS: fractional shortening, EF: ejection fraction IVST: interventricular septum thickness, PWT: posterior wall thickness, LVMI: left ventricular mass index, CIMT: carotid intima-media thickness. 
Serum levels of Ph, ALP, FBS, Triglycerides, ESR $1^{\text {st }}$ hour, ESR $2^{\text {nd }}$ hour and CRP were significantly increased in patients group compared to the controls $(\mathrm{P}<0.01)$. However, there were a statistically significant decrease in $\mathrm{Ca}$, albumin, total protein, $\mathrm{HDL}$ and $\mathrm{Hb}$ in patients group compared to the controls $(\mathrm{P}<0.01)$ (table 3$)$.

Table (3). Comparison between laboratory data of patients and the controls

\begin{tabular}{llll}
\hline & $\begin{array}{l}\text { Patients } \\
(\mathbf{n o}=\mathbf{4 0})\end{array}$ & $\begin{array}{l}\text { Control } \\
(\mathbf{n o = 2 0})\end{array}$ & P value \\
\hline $\mathrm{Ca}(\mathrm{mg} / \mathrm{dl})$ & $8.1 \pm .98$ & $9.4 \pm .6$ & $<0.01$ \\
$\mathrm{Ph}(\mathrm{mg} / \mathrm{dl})$ & $6.9 \pm 1.4$ & $3.9 \pm .46$ & $<0.01$ \\
AST (IU/L) & $17.4 \pm 7.2$ & $21.3 \pm 7.0$ & $\mathrm{NS}$ \\
ALT (IU/L) & $29.7 \pm 15.2$ & $22.8 \pm 7.2$ & $<0.05$ \\
Albumin(g/dl) & $3.1 \pm .82$ & $4.3 \pm .55$ & $>0.05$ \\
Total protein(g/dl) & $7.1 \pm .73$ & $7.6 \pm .41$ & $<0.01$ \\
ALP(IU/L) & $182.5 \pm 98.0$ & $78.5 \pm 10.3$ & $<0.01$ \\
Urea (mg/dl) & $121.8 \pm 18.7$ & $22.2 \pm 7.9$ & $<0.01$ \\
Creatinine (mg/dl) & $7.7 \pm .91$ & $.9 \pm .3$ & $<0.01$ \\
eGFR(ml/min/1.73m2) & $12.4 \pm 9.2$ & $115.7 \pm 23.6$ & $<0.01$ \\
Cholestrol(mg/dl) & $161.5 \pm 36.5$ & $146.4 \pm 34.6$ & $\mathrm{NS}$ \\
Triglcerides(mg/dl) & $228.2 \pm 99.5$ & $153.2 \pm 13.8$ & $<0.01$ \\
LDL-C(mg/dl) & $104.2 \pm 45.8$ & $110.8 \pm 28.3$ & $\mathrm{NS}$ \\
HDL-C(mg/dl) & $32.8 \pm 3.9$ & $55.0 \pm 6.9$ & $<0.01$ \\
RBS(mg/dl) & $139.2 \pm 55.1$ & $104.1 \pm 22.7$ & $<0.01$ \\
Hb(g/dl) & $9.1 \pm 1.2$ & $12.6 \pm 1.1$ & $<0.01$ \\
CRP(mg/l) & $51.6 \pm 47.3$ & $4.8 \pm 0.9$ & $<0.01$ \\
ESR 1st H(mm/h) & $67.2 \pm 36.0$ & $7.5 \pm 1.9$ & $<0.01$ \\
ESR 2nd H(mm/h) & $102.9 \pm 37.0$ & $14.9 \pm 2.3$ & $<0.01$ \\
\hline
\end{tabular}

$\mathrm{P}<0.05=$ significant, $\mathrm{P}<0.01=$ highly significant

$\mathrm{Ca}$, calcium; Ph, phosphorus; AST, aspartate aminotranseferase; ALT, alanine aminotranseferase; ALP, alkaline phosphatase; eGFR, estimated glomerular filteration rate; LDL-C, low density lipoprotein cholesterol; HDL-C, high density lipoprotein cholesterol; RBS, random blood sugar; Hb, hemoglobin; $\mathrm{CRP}, \mathrm{C}$ reactive protein; ESR, erythrocyte sedimentation rate.

Table (4). Specific Laboratory data of the patients and control group

\begin{tabular}{llll}
\hline & $\begin{array}{l}\text { Patients } \\
(\mathbf{n o = 4 0})\end{array}$ & $\begin{array}{l}\text { Control } \\
(\mathbf{n o = 2 0})\end{array}$ & P value \\
\hline 25OH VIT D $(\mathrm{nmol} / \mathrm{l})$ & $57.7 \pm 31.7$ & $97.1 \pm 47.4$ & $<0.01$ \\
PTH $(\mathrm{pg} / \mathrm{ml})$ & $600.3 \pm 490.9$ & $194.3 \pm 86.1$ & $<0.01$ \\
Osteoprotogerin(pmol/l) & $17.1 \pm 6.9$ & $5.3 \pm 1.6$ & $<0.01$ \\
Fetuin(ng/ml) & $32.5 \pm 7.9$ & $60.3 \pm 16.0$ & $<0.01$ \\
\hline
\end{tabular}

$\mathrm{P}<0.05=$ significant, $\mathrm{P}<0.01=$ highly significant

$25 \mathrm{OH}$ VIT D, vitamin D; PTH, parathormone;

Serum levels of PTH and Osteoprotegerin were significantly increased in patients group compared to the controls $(\mathrm{P}<0.01)$ (Table 4). However, there were a statistically significant decrease in Vit D and Fetuin in patients group compared to the controls $(\mathrm{P}<0.01)$ (table 4$)$.

Table (5). Comparison between hemodialysis patients without valvular calcification (Group A) and with valvular calcification (Group B)

\begin{tabular}{|c|c|c|c|}
\hline Variables & Group A $(n=10)$ & Group B $(n=30)$ & p-value \\
\hline Age (years) & $45.62 \pm 1.54$ & $58.54 \pm 8.10$ & $<0.01$ \\
\hline Duration of hemo(years) & $1.43 \pm 1.35$ & $7.15 \pm 1.83$ & $<0.01$ \\
\hline Laboratory data Urea (mg\%) & $102.24 \pm 29.99$ & $121.15 \pm 11.24$ & NS \\
\hline Creatinine $(\mathrm{mg} \%)$ & $6.08 \pm 1.85$ & $7.58 \pm 1.05$ & NS \\
\hline Albumin $(\mathrm{g} \%)$ & $3.61 \pm 0.16$ & $3.28 \pm 0.23$ & NS \\
\hline $\mathrm{Ca}(\mathrm{mg} \%)$ & $8.20 \pm 1.00$ & $8.32 \pm 1.09$ & NS \\
\hline $\mathrm{Ph}(\mathrm{mg} \%)$ & $4.62 \pm 0.99$ & $7.14 \pm 1.5$ & $<0.01$ \\
\hline $\mathrm{Ca} \times \mathrm{P}(\mathrm{mg} 2 / \mathrm{d} 12)$ & $37.51 \pm 7.37$ & $60.52 \pm 10.28$ & $<0.01$ \\
\hline $25 \mathrm{OH}$ VIT D (nmol/l) & $63.4 \quad 9.3$ & $31.7 \quad 11.8$ & $<0.01$ \\
\hline $\mathrm{PTH}(\mathrm{pg} / \mathrm{ml})$ & $596.47 \pm 535.82$ & $412.45 \pm 363.03$ & NS \\
\hline Osteoprotogerin $(\mathrm{pmol} / \mathrm{l})$ & $9.3 \pm 1.2$ & $23.7 \pm 2.4$ & $<0.01$ \\
\hline Fetuin $(\mathrm{ng} / \mathrm{ml})$ & $40.7 \pm 7.8$ & $24.5 \pm 5.6$ & $<0.01$ \\
\hline \multicolumn{4}{|l|}{ Echocardiographic data } \\
\hline $\mathrm{EDD}(\mathrm{mm})$ & $50.83 \pm 7.28$ & $49.44 \pm 9.54$ & NS \\
\hline $\mathrm{ESD}(\mathrm{mm})$ & $33.60 \pm 6.96$ & $36.99 \pm 9$ & NS \\
\hline $\mathrm{FS}(\%)$ & $39.57 \pm 9.50$ & $34.59 \pm 6.92$ & $<0.01$ \\
\hline $\mathrm{EF}(\%)$ & $65.24 \pm 9.28$ & $57.51 \pm 8.97$ & $<0.01$ \\
\hline $\operatorname{IVSTd}(\mathrm{mm})$ & $11.05 \pm 2.16$ & $11.67 \pm 2.07$ & NS \\
\hline PWTd(mm) & $10.05 \pm 2.20$ & $11.83 \pm 1.53$ & $<0.01$ \\
\hline Drugs Calcium (mg/day) & $1857.14 \pm 654.65$ & $3384.62 \pm 891.93$ & $<0.01$ \\
\hline Alphacalcidol $(\mu \mathrm{g} / \mathrm{wk})$ & $2.93 \pm 0.33$ & $2.06 \pm 0.76$ & $<0.01$ \\
\hline
\end{tabular}

$\mathrm{P}<0.05=$ significant, $\mathrm{P}<0.01=$ highly significant

Ca, calcium; Ph, phosphorus; CaxP, calcium phosphorus end products; 25OH VIT D, vitamin D; PTH, parathormone; EDD, end diastolic dimension; ESD, end systolic dimension; FS, fractional shortening; EF, ejection fraction; IVST, interventricular septum thickness; PWT, posterior wall thickness; LVMI, left ventricular mass index; CIMT, carotid intima-media thickness.

Serum level of $\mathrm{Ph}$, and Osteoprotegerin were significantly increased in patients with valvular calcification compared to patients without valvular calcifications $(\mathrm{P}<0.01)$ while Vit $\mathrm{D}$ and fetuin were significantly decreased in patients with valvular calcification $(\mathrm{P}<0.01)$. Also, FS and EF were significantly decreased in patients with valvular calcification $(\mathrm{P}<0.05 \&<0.01)$ with significant increase in PWT in the same group $(\mathrm{P}<0.05)$ (table 5).

The level of Vit D and Fetuin were negatively correlated with Urea, Creatinine, CRP, PTH and Osteoprotegerin. However, they were positively correlated with each other and with HDL and eGFR. While, the level of osteoprotegerin and PTH were positively correlated with Urea, Creatinine, CRP and with each other, they were negatively correlated with 
HDL and eGFR (table 6).

CIMT was positively correlated with LVMI ( $\mathrm{r} .49, \mathrm{P}<.01)$, PWT (r .3, P .01), urea (r .49, P<.01), creatinine (r .57, P <.01), CRP (r .3, P .01), Ca ( $\mathrm{r} .58, \mathrm{P}<.01)$ and was negatively correlated with EF\% ( $\mathrm{r}-.35, \mathrm{P}<.01)$, eGFR $(\mathrm{r}-.43, \mathrm{P}<.01)$, HDL $(\mathrm{r}-.52, \mathrm{P}<.01)$, vitamin $\mathrm{D}(\mathrm{r}-.49, \mathrm{P}<.01)$ and Feutin (r .68, $\mathrm{P}<.01$ ) (table 7).

LVMI was positively correlated with CIMT (r .49, $\mathrm{P}<.01$ ), urea $(\mathrm{r} .83, \mathrm{P}<.01)$, creatinine $(\mathrm{r} .86, \quad \mathrm{P}<.01)$ and osteoprotogen ( $\mathrm{r} .26, \mathrm{P} .04)$ and was negatively correlated with eGFR ( $\mathrm{r}-.73, \mathrm{P}<.01)$, HDL $(\mathrm{r}-.82, \mathrm{P}<.01)$, vitamin $\mathrm{D}(\mathrm{r}-.36$, $\mathrm{P}<.01)$ and fetuin $(-.37, \mathrm{P}<.01)$ (table 7 ).

PWT was positively correlated with CIMT (r .3, P.01), urea ( $\mathrm{r} .63, \mathrm{P} .01)$ and creatinine ( $\mathrm{r} .4, \mathrm{P} .01)$ and was negatively correlated with eGFR ( $\mathrm{r}-.5, \mathrm{P}$.01) (table 7).

IVST was positively correlated with urea ( $\mathrm{r} .72, \mathrm{P} .02)$, creatinine (r .3, P .01) and was natively correlated with e GFR $(\mathrm{r}-.4, \mathrm{P} .01)$ and vitamin D level $(\mathrm{r} .-3, \mathrm{P}<.01)($ table 7$)$.

Table (6). Correlation between Vit D, Osteoprotogerin, PTH \& Fetuin and other parameters

\begin{tabular}{|c|c|c|c|c|c|c|c|c|}
\hline & \multicolumn{2}{|c|}{ 25(OH)-Vit D } & \multicolumn{2}{|c|}{ Osteoprotegerin } & \multicolumn{2}{|c|}{ PTH } & \multicolumn{2}{|c|}{ Fetuin } \\
\hline & $\mathbf{R}$ & $\mathbf{P}$ & $\mathbf{R}$ & $\mathbf{P}$ & $\mathbf{R}$ & $\mathbf{P}$ & $\mathbf{R}$ & $\mathbf{P}$ \\
\hline Urea & -.41 & $<.01$ & .68 & $<.01$ & .37 & $<.01$ & -.72 & $<.01$ \\
\hline Creatinine & -.41 & $<.01$ & .65 & $<.01$ & .38 & $<.01$ & -.72 & $<.01$ \\
\hline eGFR & .42 & $<.01$ & -.43 & $<.01$ & -.41 & $<.01$ & .36 & $<.01$ \\
\hline CRP & -.41 & $<.01$ & .44 & $<.01$ & .41 & $<.01$ & -.53 & $<.01$ \\
\hline $\mathrm{Ca}$ & -.3 & NS & -.04 & NS & .003 & NS & .2 & NS \\
\hline HDL-C & .44 & $<.01$ & -.56 & $<.01$ & -.36 & $<.01$ & .69 & $<.01$ \\
\hline PTH & -.32 & .01 & .46 & $<.01$ & & & -.38 & $<.01$ \\
\hline Osteoprotogerin & -.29 & .02 & & & .46 & $<.01$ & -.62 & $<.01$ \\
\hline Fetuin & .43 & $<.01$ & -.62 & $<.01$ & -.27 & .04 & & \\
\hline
\end{tabular}

$\mathrm{P}<0.05=$ significant, $\mathrm{P}<0.01=$ highly significant

$\mathrm{Ca}$, calcium; eGFR, estimated glomerular filtration rate; HDL, high density lipoprotein cholesterol; CRP, C reactive protein; ESR, erythrocyte sedimentation rate; EDD: end diastolic dimension, Vit D, vitamin D; PTH, parathormone; LVMI: left ventricular mass index, CIMT: carotid intima-media thickness.

Table (7). Correlation between echcardiographic findings, CIMT and other parameters

\begin{tabular}{|c|c|c|c|c|c|c|c|c|c|c|}
\hline & \multicolumn{2}{|c|}{ LVMI } & \multicolumn{2}{|c|}{ CIMT } & \multicolumn{2}{|c|}{ EF\% } & \multicolumn{2}{|c|}{ PWT } & \multicolumn{2}{|c|}{ IVST } \\
\hline & $\mathbf{R}$ & $\mathbf{P}$ & $\mathbf{R}$ & $\mathbf{P}$ & $\mathbf{R}$ & $\mathbf{P}$ & $\mathbf{R}$ & $\mathbf{P}$ & $\mathbf{R}$ & $\mathbf{P}$ \\
\hline LVMI & & & .49 & $<.01$ & -.2 & NS & .4 & $<.01$ & .3 & $<0.01$ \\
\hline CIMT & .49 & $<.01$ & & & -.35 & $<.01$ & .3 & .01 & .5 & NS \\
\hline $\mathrm{EF} \%$ & -.2 & NS & -.35 & $<.01$ & & & -.3 & NS & -.3 & NS \\
\hline PWT & .4 & $<.01$ & .3 & .01 & -.3 & NS & & & .3 & $<0.01$ \\
\hline IVST & .3 & $<.01$ & .5 & NS & -.3 & NS & .3 & $<.01$ & & \\
\hline Urea & .83 & $<.01$ & .49 & $<.01$ & -.6 & NS & .63 & .01 & .72 & $<0.05$ \\
\hline eGFR & -.73 & $<.01$ & -.43 & $<.01$ & .4 & NS & -.5 & .01 & -.4 & $<0.05$ \\
\hline HDL-C & -.82 & $<.01$ & -.52 & $<.01$ & .3 & NS & -64 & $<.01$ & -.5 & $<0.01$ \\
\hline CRP & .2 & NS & .3 & .01 & -.3 & NS & .2 & NS & .2 & NS \\
\hline $\mathrm{Ca}$ & .2 & NS & .3 & .04 & .06 & NS & .08 & NS & .07 & NS \\
\hline $\mathrm{Ph}$ & .3 & NS & .1 & NS & .2 & NS & .1 & NS & .1 & NS \\
\hline CaxP & .25 & NS & .2 & NS & .1 & NS & .09 & NS & .08 & NS \\
\hline $25(\mathrm{OH})$-vit D & -.36 & $<.01$ & -.49 & $<.01$ & .13 & NS & -.3 & $<0.01$ & -.3 & $<0.01$ \\
\hline PTH & .2 & NS & .1 & NS & -.1 & NS & .8 & NS & .2 & NS \\
\hline Fetuin & -.37 & $<.01$ & -.68 & $<.01$ & .1 & NS & -.3 & .02 & -.4 & $<0.05$ \\
\hline
\end{tabular}

$\mathrm{P}<0.05=$ significant, $\mathrm{P}<0.01=$ highly significant

$\mathrm{Ca}$, calcium; Ph, phosphorus; AST,aspartate aminotranseferase; ALT, alanine aminotranseferase; ALP, alkaline phosphatase; eGFR, estimated glomerular filteration rate; LDL-C, low density lipoprotein cholesterol; HDL-C, high density lipoprotein cholesterol; RBS, random blood sugar; Hb, hemoglobin; CRP, C reactive protein; ESR, erythrocyte sedimentation rate; EDD: end diastolic dimension, ESD: end systolic dimension, FS: fractional shortening, EF: ejection fraction IVST: interventricular septum thickness, PWT: posterior wall thickness, LVMI: left ventricular mass index, CIMT: carotid intima-media thickness.

A multiple stepwise linear regression analysis was performed to determine the independent factors of valvular calcification in hemodialysis patients. Variables significantly associated with valvular calcification and other known to have effect on valvular calcification were introduced in the model. After adjustment for parameters found significant in the univariate analysis, the independent predictors of valvular calcification were increased age of the patients, duration of hemodialysis, CaxP product, serum $\mathrm{Ph}$, osteoprotogerin level and decreased vitamin $\mathrm{D}$ and feutin $\mathrm{A}$ level and also increased PW thickness, LVMI and CIMT and reduced EF\%.

\section{Discussion}

Cardiovascular disease is the leading cause of death in chronic dialysis patients. [31]. The presence as well as the extent of cardiovascular calcification has been demonstrated to be predictors of cardiovascular and all-cause mortality in 
dialysis patie nts [32 \&33].

Patients with end-stage renal disease (ESRD) are frequently burdened with calcific valvular heart disease. Valvular involvement in ESRD is most commonly manifested as mitral annular calcification and aortic valve calcification. Both mitral and aortic valve calcification (MAC) occur more frequently and at younger age in those with ESRD than in those with normal renal function [34 \& 35].

London and his colleagues reported that $63.8 \%$ of their hemodialysis patients had arterial calcification [4]. Coronary artery calcification has also been shown to be more prevalent after the onset of dialysis, being present in $65 \%$ of those patients [11].

Kidney disease improving global outcomes (KDIGO) recommended that an echocardiogram can be used to detect the presence or absence of valvular calcification, as reasonable alternative to computed tomography based imaging in patients with CKD and hemodialysis patients, as echocardiography is an easier technique with a reasonable sensitivity, as compared with the more expensive CT-based techniques and may yield comparable information [36].

This cross sectional study was carried out on 40 adult hemodialysis patients and 20 age and sex matched healthy control subjects.

Our study revealed high frequency of valvular calcification (75\%). Of 40 hemodialysis patients, 12 patients had isolated aortic calcification, 8 had isolated mitral calcification and 10 had both mitral and aortic calcification, none had pulmonary or tricuspid valve calcification. 15 patients had aortic regurge and 3 patients had aortic stenosis while 10 patients had mitral regurge .

Preponderance of valvular calcifications in ESRD patients was detected in many previous studies. Ribeiro and his colleagues found among 92 patients whose mean age was 60 years, $44 \%$ had mitral valve calcifications on echocardiography, and $52 \%$ had aortic valve calcifications [37]. In other study, mitral valve calcifications were reported in $45 \%$, and aortic valve calcifications in $34 \%$ of patients, while both valves were affected in $21 \%$ of the patients studied [38].

In addition, the Cardiovascular Health Study (C H S) showed a high prevalence of CKD in adults with combined mitral annular calcification, aortic annular calcification and aortic valvular stenosis [39].

In the present study, valvular calcification was significantly higher in HD patients than in healthy controls. HD patients were classified into two groups according to the presence or absence of valvular calcification. HD patients with valvular calcification were older in age, with a longer HD duration, showed higher $\mathrm{P}$ level and $\mathrm{Ca} \times \mathrm{P}$ product indicating that these factors may be responsible for the development of valve calcification. Also, they showed lower EF \% and were compared to patients without valvular calcification and were on higher doses of calcium and lower doses of alphacalcidol. On the other hand, our study showed no significant association between serum calcium and PTH with valvular calcification.
In our study, there was a significant increase in CIMT in HD patients group versus the control group $((\mathrm{P}<0.01)$ which is in agreement with the results of Masho and Shigematsu who stated that CKD patients are well recognized to have advanced arteriosclerosis with vascular medial calcification and with high risk of cardiovascular death[40]. In two studies, Blacher and his colleagues indicated that the frequency of atherosclerotic plaques is far higher in dialysis patients not only in comparison with healthy subjects but also in comparison with patients without renal diseases who are matched for traditional cardiovascular risk factors [41 \& 42]. Moreover, Kawagishi and his colleagues showed that CIMT was significantly higher in HD patients than in age- and gender-matched control subjects [43]. CIMT remained a consistent predictor of fatal cardiovascular events after statistical adjustment for LVM and other risk factors indicates that this measurement bears a prognostic value also on a high-risk population like the dialysis population, a $0.1-\mathrm{mm}$ increase in CIMT predicts a $24 \%$ higher risk for cardiovascular death [14 \& 44].

In our study, we confirmed the results of Francesco and his colleagues (2001), that CIMT is strongly related to LV hypertrophy [14]. In our study, CIMT was positively correlated with LVMI and PWT. London and his colleagues were the first to demonstrate that CIMT is strongly associated with the thickness of the posterior wall and with LVMI [45].

Also in the present study, valvular calcification and the increased CIMT and LVMI in HD patients were inversely correlated to serum level of $25(\mathrm{OH})$-vitamin D. Our study is in agreement with Davies and his colleagues who showed that vascular calcification was inversely correlated to serum level of 25(OH)-vitamin D [46], and with other retrospective studies by Mizobuchi and his colleagues who showed similar findings but were not correlated with serum $\mathrm{Ca}, \mathrm{P}$, and $\mathrm{PTH}$ levels [47].

Drechsler and his colleagues investigated the impact of vitamin D status on cardiovascular outcomes in hemodialysis and found that severe vitamin D deficiency was strongly associated with sudden cardiac death, cardiovascular events and mortality [48].

There were no significant correlations between the parathormone level and the CIMT or the LVMI, which points to the fact the parathormone level has a minor role in cardiovascular risk factor in hemodialysis patients.

There were no significant correlations between the level phosporus and the CIMT or the LVMI but our study showed significant correlations between the serum $\mathrm{Ph}$ level and valvular calcification. A study by Prosdocimo and his colleague have shown that elevated extracellular inorganic phosphate act synergistically to induce calcification, which is correlated with a progressive reduction in extracellular pyrophosphate [49].

Also our study detected lower levels of serum fetuin A in the patients group compared to the control group, with a significant inverse correlation between fetuin A and creatinine while fetuin A shows a significant positive correlation with eGFR. These findings are in agreement with those of Caglar 
and his colleague who reported low levels of serum fetuin A in end stages CKD [50]. fetuin A levels decline during the course of the disease progression and a relevant decrease in fetuin A is linked to a greater decline in renal function [51].

Concerning the relationship between fetuin $\mathrm{A}$ and calcification, our results detected a negative association between fetuin A levels and CIMT and valvular calcification in the patients group. This finding is in agreement with those of Moe and Chen and Wang and his colleagues, they stated that fetuin $\mathrm{A}$ is a potent inhibitor of vascular calcification and its low levels were associated with coronary artery calcification [52 \& 53]. Also in a recent study, fetuin-A showed a significant negative association with CIMT[[26].

Regarding osteoprotegerin, we detected a significant elevation in OPG levels in the patients group as compared to the control group. These results are in agreement with those of Kazama and his colleagues who reported elevated OPG levels in chronic kidney disease patients and suggested that accumulated OPG in the circulation may be a uremic toxin that increases the skeletal resistance to PTH[54].

We detected significant positive association between serum OPG levels, and serum creatinine and a strong negative association of OPG with eGFR. Also, our results showed a strong association between OPG levels and CIMT and valvular calcification. A recent study documented a positive association of CIMT with OPG [26]. Grzegorzewska and Mlot reported that elevated serum OPG levels were found to be correlated with the rapid progression of coronary artery calcification and mortality [55].

Our study detected a strong inverse association between fetuin $\mathrm{A}$ and OPG. This finding suggests that changes occurring in the levels of fetuin A and OPG with the presence of uremic milieu can result in the occurrence of vascular calcification in a CKD patient and these biomarkers are activated and worsen progressively as renal function declines [51].

\section{Conclusion}

Echocardiogram can be used to evaluate cardiac structure and function and to detect valvular calcification. Measurement of CIMT by carotid ultrasound is noninvasive and relatively inexpensive. Echocardiogram and carotid ultrasound can be repeatedly performed with no adverse effects to evaluate cardiovascular performance in hemodialysis patients.

Valvular calcification in hemodialysis patients is related to many factors, control of the modifiable factors is necessary to control the degree of calcification. HD patients with valvular calcification were older in age, with a longer hemodialysis duration, showed higher $\mathrm{Ph}$ level, $\mathrm{Ca} \times \mathrm{P}$ product and OPG level and showed lower 25(OH)-vitamin D and fetuin A level. Also they showed lower EF \% and were on lower doses of alphacalcidol and higher doses of calcium compared to patients without valvular calcification. So, our study points to the importance of administration of active vitamin D derivatives to decrease the risk of valvular calcification and atherosclerosis.
Parathormone level has a minor role as a cardiovascular risk factor in hemodialysis patients.

Serum fetuin A and osteoprotegerin can be used as a simple, easily performed non-invasive biomarkers mirroring valvular calcification in hemodialysis patients.

Further studies should be done to assess trials for the addition of fetuin $\mathrm{A}$ in the treatment of $\mathrm{CKD}$ patients to prevent the occurrence of calcification and early death.

\section{References}

[1] Tonelli M, Muntner P, Lloyd A, Manns BJ, Klarenbach S, Pannu N, James MT, Hemmelgarn BR ,2012: Risk of coronary events in people with chronic kidney disease compared with those with diabetes: a population-level cohort study. Lancet. 1;380(9844):807.

[2] Longenecker JC, Coresh J, Powe NR, Levey AS, Fink NE, Martin A, Klag MJ. 2002: Traditional cardiovascular disease risk factors in dialysis patients compared with the general population: the CHOICE Study. J Am Soc Nephrol.;13:1918-1927.

[3] Budoff MJ, Rader DJ, Reilly MP, Mohler ER, Lash J, Yang W, Rosen L, Glenn M, Teal V, Feldman HI.,2011: Relationship of estimated GFR and coronary artery calcification in the CRIC (Chronic Renal Insufficiency Cohort) Study. Am J Kidney Dis. ;58:519-526

[4] London GM, Guérin AP, Marchais SJ, Métivier F, Pannier B, Adda H., 2003: Arterial media calcification in end-stage renal disease: impact on all-cause and cardiovascular mortality. Nephrol Dial Transplant.;18:1731-1740.

[5] Disthabanchong S., 2013: Lowering vascular calcification burden in chronic kidney disease: Is it possible? World J Nephrol. 6;2(3):55

[6] Dellegrottaglie S, Sanz J, Rajagopalan S., 2006: Molecular determinantsof vascular calcification: A bench to bedside view. Curr Mol Med; 6: 5524.

[7] Shanahan CM, Cary NR, Salisbury JR, Proudfoot D, Weissberg PL, Edmonds ME., 1999:,Medial localization of mineralizationregulating proteins in association with Mönckeberg's sclerosis: Evidence for smooth muscle cell-mediated vascular calcification. Circulation; 100: 212176.

[8] Vattikuti R, Towler DA., 2004: Osteogenic regulation of vascular calcification: An early perspective. Am J Physiol Endocrine Metab; 286: E6696.

[9] Ikee R, Honda K, Oka M, Maesato K, Mano T, Moriya H, Ohtake T, Kobayashi S., 2008:Association of heart valve calcification with malnutrition-inflammation complex syndrome, betamicroglobulin, and carotid intima media thickness in patients on hemodialysis. Ther Apher Dial; 12: 4468 .

[10] Rochelle C , Corretti M \& Henrich W., 2010:Valvular Heart Disease In Patients With End-Stage Renal Disease. J Am Soc Nephrol 20: 388-396.

[11] Block GA, Spiegel DM, Ehrlich J, Mehta R, Lindbergh J, Dreisbach A, Raggi P., 2005: Effects of sevelamer and calcium on coronary artery calcification in patients new to hemodialysis. Kidney Int; 68: 181824. 
[12] Cobble M and Bale B. , 2010:Carotid intima-media thickness: Knowledge and application to every day practice.; 122 (1): 28

[13] Ossareh S, Alaei A and Saedi D., 2011: Carotid intima-media thickness in maintenance hemodialysis patients: role of cardiovascular risk factor.; 5 (3): 1174.

[14] Francesco A B , Francesco M, Giovanni T and Carmine Z., 2001: Prognostic Value of Ultrasonographic Measurement of Carotid Intima Media Thickness in Dialysis Patients.J Am Soc Nephrol ; 12:242464.

[15] Saritas T, Tascilar E, Abaci A, Yozgat Y, Dogan M, Dundaroz R, Hasimi A, Yesilkaya E, Lenk MK and Kilic A., 2010:Importance of plasma N-terminal pro B-type natriuretic peptide, epicardial adipose tissue, and carotid intima-media thicknesses in asymptomatic obese children. Pediatr Cardiol.; 31(6):79.

[16] Lee CT, Tsai YC, Ng HY, Su Y, Lee WC, Lee LC, Chiou TT, Liao SC, Hsu KT., 2009: Association between C-reactive protein and biomarkers of bone and mineral metabolism in chronic hemodialysis patients: A cross-sectional study. J Ren Nutr; 19: 2227.

[17] Wang AY, Lam CW, Wang M, Chan IH, Yu CM, Lui SF, Sanderson JE. 2008 Increased circulating inflammatory proteins predict a worse prognosis with valvular calcification in endstage renal disease: A prospective cohort study. Am J Nephrol; 28: 6653.

[18] Chertow GM, Raggi P, Chasan-Taber S, Bommer J, Holzer H, Burke SK,. 2004: Determinants of progressive vascular calcification in haemodialysis patients. Nephrol Dial Transplant. ;19:1489-1496.

[19] Galassi A, Spiegel DM, Bellasi A, Block GA, Raggi P., 2006: Accelerated vascular calcification and relative hypoparathyroidism in incident haemodialysis diabetic patients receiving calcium binders. Nephrol Dial Transplant. ;21:3215-3222.

[20] Leea, $C$, Chuab S, Hsuc C, Tsaia Y, 2013: Biomarkers associated with vascular and valvular calcification in chronic hemodialysis patients Disease Markers ; 34; 229-235

[21] Davies MR, Lund RJ, Hruska KA:, 2003: BMP-7 is an efficacious treatment of vascular calcification in a murine model of atherosclerosis and chronic renal failure. J Am Soc Nephrol ; 14: 1559-1567.

[22] Mizobuchi M, Finch JL, Martin DR, Slatopolsky E: 2007: Differential effects of vitamin D receptor activators on vascular calcification in uremic rats. Kidney Int ; 72: 709-715.

[23] Schafer C, Heiss A, Schwarz A, Westenfeld R, Ketteler M, Floege J, Muller-Esterl W, Schinke T, Jahnen-Dechent W., 2003: The serum protein alpha Heremans-Schmid glycoprotein/fetuin-A is a systemically acting inhibitor of ectopic calcification. J Clin Invest. ;14:357-366.

[24] Reynolds JL, Skepper JN, McNair R, Kasama T, Gupta K, Weissberg PL, Jahnen-Dechent W, Shanahan CM., 2005: Multifunctional roles for serum protein fetuin-a in inhibition of human vascular smooth muscle cell calcification. J Am Soc Nephrol.;14:2920-2930

[25] Ketteler M, Bongartz P, Westenfeld R, Wildberger JE, Mahnken AH, Bohm R, Metzger T, Wanner C, Jahnen-Dechent W, Floege J., 2003: Association of low fetuin-A (AHSG) concentrations in serum with cardiovascular mortality in patients on dialysis: a cross-sectional study. Lancet. ;14:827-833.

[26] Pateinakis P, Papagianni A, Douma S, Efstratiadis G, and Memmos D., 2013: Associations of fetuin-A and osteoprotegerin with arterial stiffness and early atherosclerosis in chronic hemodialysis patients. BMC Nephrol. ; 14: 122.

[27] Aoki A, Murata M, Asano T, Ikoma A, Sasaki M, Saito T, Otani T, Jinbo S, Ikeda N, Kawakami M, Ishikawa SE., 2013: Association of serum osteoprotegerin with vascular calcification in patients with type 2 diabetes. Cardiovas Diabetol.;14:11.

[28] Speer G, Fekete BC, El Hadj Othmane T, Szabo T, Egresits J, Fodor E, Kiss I, Logan AG, Nemcsik J, Szabo A, Nemeth ZK, Szathmari M, Tisler A., 2008:Serum osteoprotegerin level, carotid-femoral pulse wave velocity and cardiovascular survival in haemodialysis patients. Nephrol Dial Transplant. ;14:3256-3262

[29] Morena M, Terrier N, Jaussent I, Leray-Moragues H, Chalabi L, Rivory JP, Maurice F, Delcourt C, Cristol JP, Canaud B, Dupuy AM., 2006: Plasma osteoprotegerin is associated with mortality in hemodialysis patients. J Am Soc Nephrol. ;14:262-270

[30] Gottdiener J.S. , Bendnarz I., Devereaux R., 2004:American Society of Echocardiography recommendations for use of echocardiography inclinical trials. Journal of American Society ofEchocardiography; ; $17: 1086: 1119$

[31] Tsai YC, Lee CT, Huang TL, Cheng BC, Kuo CC, Su Y, Ng HY, Yang CC, Chuang FR, Liao SC., 2007: Inflammatory marker but not adipokine predicts mortality among long-term hemodialysis patients. Mediators Inflamm ; 19819895.

[32] Blacher J, Guerin AP, Pannier B, Marchais SJ, London GM ,2001:Arterial calcifications, arterial stiffness and cardiovascular risk in end-stage renal disease. Hypertension; 38: 9942

[33] Wang AY, Wang M, Woo J, Lam CW, Li PK, Lui SF, Sanderson JE., 2003: Cardiac valve calcification as an important predictor for all-cause mortality and cardiovascular mortality in longterm peritoneal dialysis patients: A prospective study. J Am Soc Nephrol ; 14: 1168

[34] Ernesto U , Waqas A \& Martin A., 2003: Valvular and Perivalvular Abnormalities in End-Stage Renal Disease. The American Journal of Medical Sciences; 325:2242.

[35] Raggi P, Bommer J, Glenn M., 2004: Valvular Calcification in Hemodialysis Patients Randomized to Calcium-Based Phosphorus Binders or Sevelamer. J Heart Valve Dis ; 13: 1.

[36] Moe M, Drueke T, Block A., 2009: KDIGO Clinical Practice Guideline for the Diagnosis, Evaluation, Prevention, and Treatment of Chronic Kidney Disease-Mineral and Bone Disorder(CKD-MBD).kidney international ; 76 : 49.

[37] Ribeiro S, Ramos A\& Brandao A., 1998: Cardiac valve calcification in haemodialysis patients: Role of calcium-phosphate metabolism. Nephrol Dial Transplant. ; 13: 202040.

[38] Raggi P, Boulay A, Chasan-Taber S,. 2008: Cardiac calcification in adult hemodialysis patients. A link between end-stage renal disease and cardiovascular disease? J Am Coll Cardiol 2008; 39: 695-701. 
[39] Barasch E, Gottdiener J, Larsen E., 2006: Cardiovascular morbidity and mortality in community-dwelling elderly individuals with calcification of the fibrous skeleton of the base of the heart and aortosclerosis (The Cardiovascular Health Study). Am J Cardiol; 97:121286.

[40] Masho Y and Shigematsu T., 2007: Arteriosclerosis and vascular calcification in chronic kidney disease (CKD) patients.Clin Calcium. 17(3):39.

[41] Blacher J, Pannier B, Guerin AP, Marchais, SJ, Safar ME, London GM. ,1998: Carotid arterial stiffness as a predictor of cardiovascular and all-cause mortality in end stage renal disease.Hypertension ; $32: 5574$.

[42] London GM, Marchais SJ, Guerin AP, Boutouyrie P, Metivier F, and De Vernejoul MC. ,2008: Association of bone activity, calcium load, aortic stiffness, and calcification in ESRD. J Am Soc Nephrol; ;19: 181835.

[43] Kawagishi T, Nishizawa Y, Konishi T, Kawasaki K, Emoto M, Shoji T, Tabata T, Inoue T, Morii H.,1995:High-resolution B-mode ultrasonography in evaluation of atherosclerosis in uremia. Kidney Int ; $48: 8826$.

[44] Saritas T, Tascilar E, Abaci A, Yozgat Y, Dogan M, Dundaroz R, Hasimi A, Yesilkaya E, Lenk MK and Kilic A., 2010: Importance of plasma N-terminal pro B-type natriuretic peptide, epicardial adipose tissue, and carotid intima-media thicknesses in asymptomatic obese children. Pediatr Cardiol. ; 31(6):79.

[45] London GM, Guerin AP, Marchais SJ, Pannier B, Safar ME, Day M, Metivier F.,1996: Cardiac and arterial interactions in end-stage renal disease. Kidney Int ; 50:600 -608.

[46] Davies MR, Lund RJ, Hruska KA., 2003: BMP-7 is an efficacious treatment of vascular calcification in a murine model of atherosclerosis and chronic renal failure. J Am Soc Nephrol ; 14: 1559-1567.

[47] Mizobuchi M, Ogata H, Koiwa F, Kinugasa E, Akizawa T., 2009: Vitamin D and vascular calcification in chronic kidney disease. Bone ; 45: 26-29.
[48] Drechsler C, Pilz S, Obermayer-Pietsch B, Verduijn M, Tomaschitz A, Krane V, Espe K,Dekker F, Brandenburg V, März W, Ritz E, Wanner C, 2010: Vitamin D deficiency is associated with sudden cardiac death, combined cardiovascular events, and mortality in haemodialysis patients. Eur Heart J; 31:2253-2261.

[49] Prosdocimo DA, Wyler SC, Romani AM, O’Neill WC, Dubyak GR., 2010: Regulation of vascularsmooth muscle cell calcification by extracellular pyrophosphate homeostasis: synergistic modulation by cyclic AMP and hyperphosphatemia. Am J Physiol Cell Physiol ; 298:702-713.

[50] Caglar K, Yilmaz MI, Saglam M, Cakir E, Kilic S, Sonmez A, Eyileten T, Yenicesu M, Oguz Y, Tasar M, Vural A, Ikizler TA, Stenvinkel P, Lindholm B., 2008:Serum fetuin-A concentration and endothelial dysfunction in chronic kidney disease. Nephron Clin Pract. 108:233-240.

[51] Cottone S, Palermo A, Arsena R, Riccobene R, Guarneri M, Mulè G., 2010: Relationship of fetuin-A with glomerular filtration rate and endothelial dysfunction in moderate-severe chronic kidney disease. JNEPHROL ; 23(01):62-69

[52] Moe SM and Chen NX., 2005: Inflammation and vascular calcification. Blood Purif.; 23:64-71.

[53] Wang AY, Woo J, Lam CW, Wang M, Chan IH, Gao P, Liu SF, Li PK, Sanderson JE., 2005: Associations of serum fetuin-A with malnutrition, inflammation, atherosclerosis and valvular calcification syndrome and outcome in peritoneal dialysis patients. Nephrol Dial Transplant. ; 20:1676-1685.

[54] Kazama JJ, Shigematsu T, Yano K, Tsuda E, Miura M, Iwasaki Y. ,2002: Increased circulating levels of osteoclastogenesis inhibitory factor (osteoprotegerin) in patients with chronic renal failure. Am J Kidney Dis.; 39:525-532.

[55] Grzegorzewska AE and Mlot M., 2004: Serum osteoprotegerin level is lower in peritoneal dialysis patients than hemodialysis ones.Rocz Akad Med Bialymst. ; 49:193-196. 